\title{
CyberKnife Radiotherapy for Skull Base Petroclival Metastases Including Dorello's Canal: Report of 10 Cases
}

\author{
Shinichiro Miyazaki ${ }^{1}$, Yuko Harada ${ }^{1}$, Yusuke Sasaki ${ }^{2}$, Takanori Fukushima ${ }^{3}$ \\ 1. CyberKnife Center, Shin-Yurigaoka General Hospital, Kawasaki, JPN 2. Neurosurgery, Tokyo General Hospital, \\ Tokyo, JPN 3. Neurosurgery, Duke University, Durham, USA
}

Corresponding author: Yuko Harada, adayuko1219@yahoo.co.jp

\begin{abstract}
Skull base petroclival metastases cause diplopia due to abducens nerve palsy. Diplopia is visually disabling, and skull base metastasis is extremely difficult to treat even with microscopic surgery. However, stereotactic radiotherapy with CyberKnife (Accuray Incorporated, Sunnyvale, California) has been very successful in 10 cases. As the abducens nerve runs through Dorello's canal in the skull base, the radiation dose and fraction were adjusted to avoid damage to the nerve. Since these metastases are not located inside the brain but in the skull base, contrast magnetic resonance imaging (MRI) combined with fluorodeoxyglucose-positron emission tomography (FDG-PET) was essential to detect the cancers.
\end{abstract}

Categories: Radiation Oncology, Neurosurgery

Keywords: skull base metastasis, abducens nerve palsy, cyberknife, dorello's canal

\section{Introduction}

Skull base metastasis causes pain or cranial nerve palsy, which are disturbing symptoms for patients. In 1981, Greenberg et al. classified the neurological findings of skull base metastases into five syndromes: orbital, parasellar, middle fossa, jugular foramen, and occipital condyle [1]. in 2018, Hayashi et al. reported metastatic tumors in the clivus or petrous, which presented diplopia due to abducens palsy. These tumors comprised $20 \%$ of skull base metastases [2] We treated 10 patients with diplopia who presented with petroclival metastases, which falls into the category of parasellar syndrome or middle fossa syndrome by Greenberg.

Since the surgical approach into the skull base is extremely difficult, the first choice of treatment is radiotherapy. The CyberKnife System (Accuray Incorporated, Sunnyvale, California) is a robotic radiosurgery system that provides highly precise stereotactic radiotherapy (SRT). SRT with CyberKnife is non-invasive, and hospitalization is not required.

Review began 09/11/2020 Review ended 09/26/2020 Published 09/28/2020

() Copyright 2020 Miyazaki et al. This is an open access article distributed under the terms of the Creative Commons Attribution License CC-BY 4.0., which permits unrestricted use, distribution, and reproduction in any medium, provided the original author and source are credited.
We have successfully treated 10 cases with skull base petroclival metastases with CyberKnife SRT. Contrast MRI and FDG-PET revealed petroclival metastases, thus we suspected the cancer should be in Dorello's canal through which the abducens nerve runs. The treatment required some adjustment to decrease the compression pressure to the abducens nerve in Dorello's canal without damaging the nerve. This is the first report to treat diplopia by treating petroclival metastasis with multi-fractionated SRT, presuming that the tumor is compressing the abducens nerve in Dorello's canal.

\section{Materials And Methods}

All the patients with diplopia underwent contrast-enhanced brain MRI and FDG-PET/CT scans to evaluate the entire brain and body prior to treatment. If the brain MRI revealed petroclival metastasis and FDG uptake was observed in the same area, it was suggested that the abducens nerve was compressed by the metastatic tumor in the petroclival area on the skull base. Standard surgery was difficult in all cases, as the tumors located in the skull base were difficult to reach manually.

Multisession stereotactic radiotherapy was performed for 10 cases using the CyberKnife G4 system. All cases presented metastatic cancer which caused abducens nerve palsy.

Tumors were tracked with the skull-tracking algorithm. The gross tumor volume (GTV) was defined as a visible tumor on enhanced MRI with images merged for target definition. GTV was considered the same as the clinical target volume (CTV). The planning target volume (PTV) included CTV and a margin of $1.2 \mathrm{~mm}$.

In order to decompress the tumor (decrease the tumor volume in order to decrease pressure to the abducens nerve) in Dorello's canal without damaging the abducens nerve, the radiation fractions were nearly doubled. 


\section{Cureus}

The treatments were on an outpatient basis and followed up every four to six months with MRI or FDG-PET.

\section{Results}

Table 1 shows the results of 10 cases.

\begin{tabular}{|c|c|c|c|c|c|c|c|c|c|c|}
\hline Case & 1 & 2 & 3 & 4 & 5 & 6 & 7 & 8 & 9 & 10 \\
\hline Histology & $\begin{array}{l}\text { pharyngeal } \\
\text { adenoid cystic } \\
\text { carcinoma }\end{array}$ & $\begin{array}{l}\text { pharyngeal } \\
\text { cancer }\end{array}$ & $\begin{array}{l}\text { pharyngeal } \\
\text { cancer }\end{array}$ & breast cancer & breast cancer & $\begin{array}{l}\text { tyyroid tolicular } \\
\text { cancer }\end{array}$ & adenocarcinoma & uterus cancer & prostate cancer & $\begin{array}{l}\text { adenocystic } \\
\text { carcinoma in } \\
\text { paranasal sinus }\end{array}$ \\
\hline Location & L & $\mathrm{L}$ & L & L & L & L & $\mathrm{R}$ & $\mathrm{R}$ & $\mathrm{R}$ & $\mathrm{R}$ \\
\hline Age & 56 & 53 & 54 & 46 & 47 & 45 & 66 & 67 & 59 & 42 \\
\hline Sex & M & $\mathrm{F}$ & M & $\mathrm{F}$ & $\mathrm{F}$ & M & M & $\mathrm{F}$ & M & $\mathrm{F}$ \\
\hline PTV (cc) & 24.3 & 9.89 & 55.58 & 11.8 & 13.5 & 3.9 & 0.37 & 7.4 & 4.8 & 6.58 \\
\hline Dose (cGy) & 4500 & 4500 & 4800 & 3500 & 4200 & 3500 & 3250 & 3800 & 4000 & 3400 \\
\hline Fraction & 15 & 8 & 10 & 8 & 7 & 5 & 5 & 5 & 5 & 5 \\
\hline $\begin{array}{l}\text { Prescription } \\
\text { isodose line } \\
\text { (\%) }\end{array}$ & 72 & 72 & 68 & or & 16 & 80 & 90 & 76 & 82 & 72 \\
\hline period & 11 months & 3 years 9 months & 3 years 5 months & 3 years 8 months & 3 years 1 month & months & year 7 months & 1 year & 8 years 5 months & 8 months \\
\hline Outcome & $\begin{array}{l}\text { Tumor } \\
\text { disappeared, } \\
\text { diplopia resolved }\end{array}$ & $\begin{array}{l}\text { Tumor } \\
\text { disappeared, } \\
\text { diplopia resolved }\end{array}$ & $\begin{array}{l}\text { Tumor } \\
\text { disappeared, } \\
\text { diplopia resolved }\end{array}$ & $\begin{array}{l}\text { Tumor } \\
\text { disappeared, } \\
\text { diplopia resolved }\end{array}$ & $\begin{array}{l}\text { Tumor } \\
\text { disappeared, } \\
\text { diplopia resolved }\end{array}$ & $\begin{array}{l}\text { decreased, } \\
\text { diplopia } \\
\text { resolved }\end{array}$ & $\begin{array}{l}\text { Tumor } \\
\text { disappeared, } \\
\text { diplopia resolved }\end{array}$ & $\begin{array}{l}\text { Tumor } \\
\text { disappeared, } \\
\text { diplopia resolved }\end{array}$ & $\begin{array}{l}\text { Tumor } \\
\text { disappeared, } \\
\text { diplopia resolved }\end{array}$ & $\begin{array}{l}\text { Tumor disappeared, } \\
\text { diplopia resolved }\end{array}$ \\
\hline
\end{tabular}

TABLE 1: Details of 10 cases

Histology, location, age, sex, PTV of tumor, radiation dose, prescription isodose line, radiation fraction, follow-up period, and outcome of 10 cases

No adverse events were observed.

PTV: planning target volume

There were three cases of pharyngeal cancer, two cases of breast cancer, one of paranasal cancer, one of uterus cancer, 1 prostate cancer, 1 lung cancer, and 1 thyroid cancer. PTV ranged from $0.37 \mathrm{cc}$ to $55.58 \mathrm{cc}$, and fractions ranged from 5 to 15 . Radiation dose ranged from $3250 \mathrm{cGy}$ to $4800 \mathrm{cGy}$. All patients recovered from diplopia.

The FDG-PETs of Case 1 before and after treatment are shown in Figure 1. Petroclival metastasis was remarkably decreased in only six months. 


\section{Cureus}

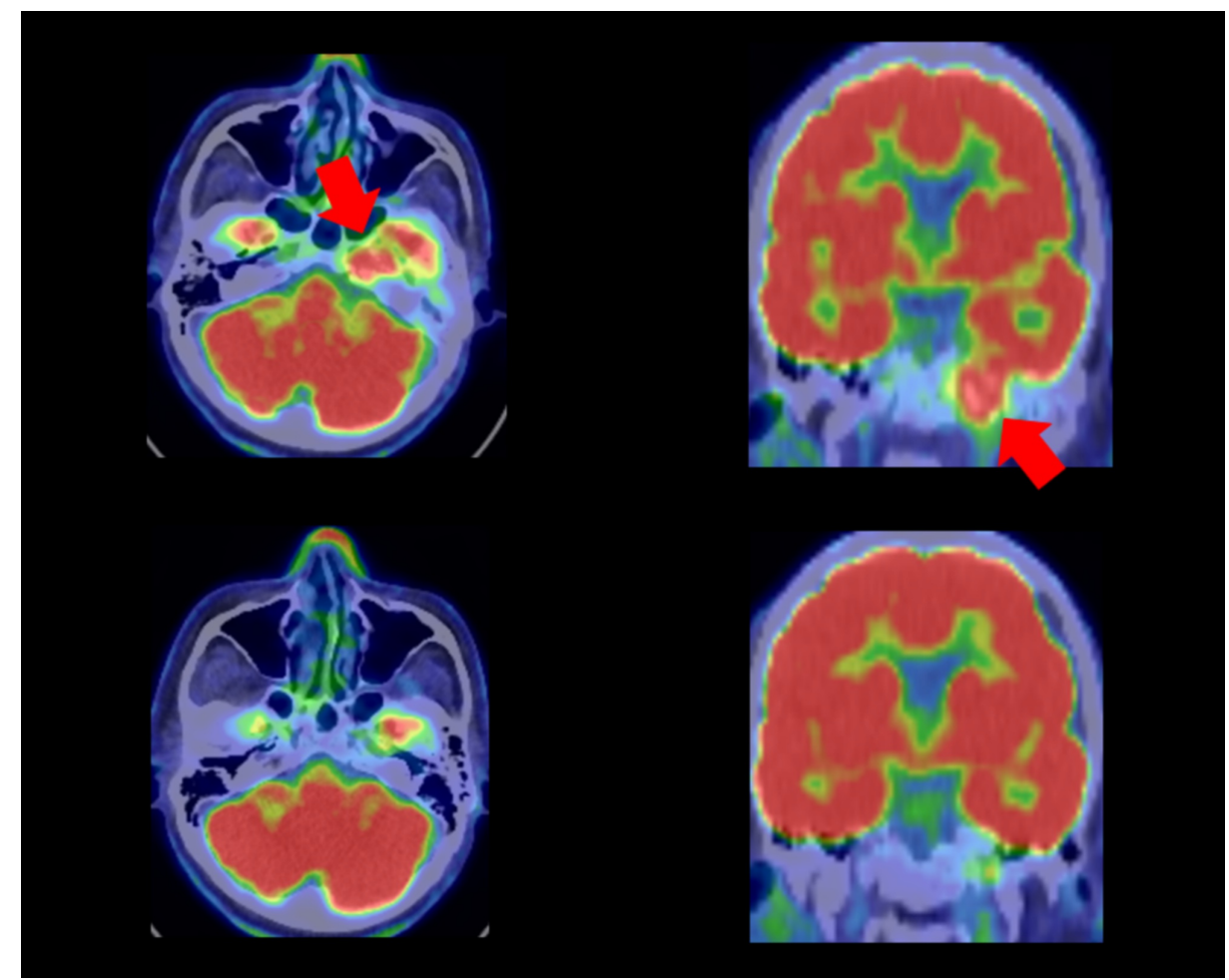

\section{FIGURE 1: FDG-PET of Case 1}

FDG-PET before CyberKnife (top) and after CyberKnife (bottom). The tumor (red arrow) disappeared after treatment.

FDG-PET: fluorodeoxyglucose-positron emission tomography

The Case 1 treatment plan of CyberKnife radiation therapy is shown in Figure 2. The contour map with isodose lines is shown drawn around the tumor.

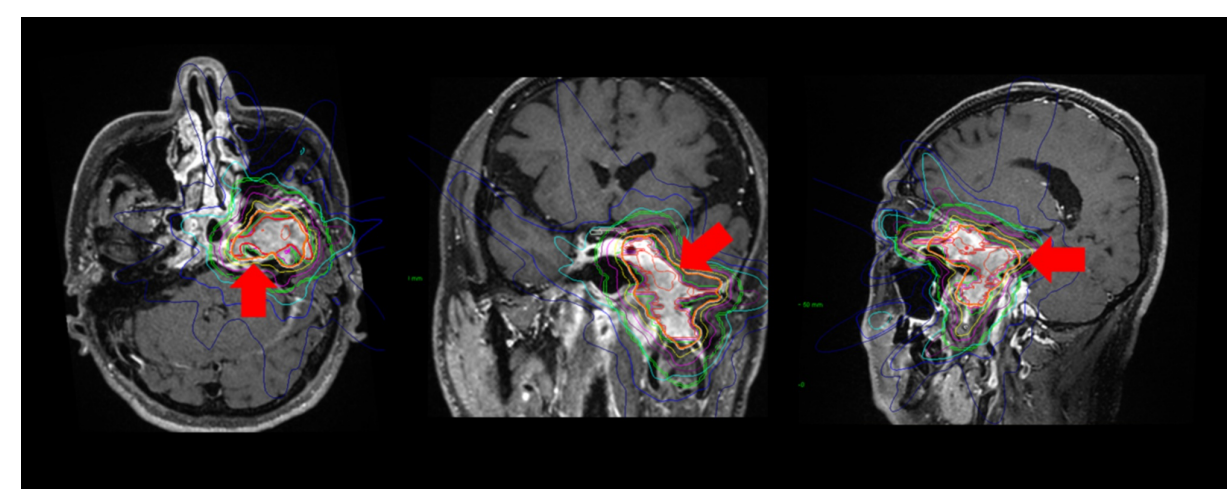

FIGURE 2: CyberKnife treatment plan for Case 1

Contour maps were drawn around the tumor (red arrow).

Contrast-enhanced MRI of Case 1 is shown in Figure 3. Petroclival metastasis was easily detected by FDGPET rather than MRI; however, MRI is more suitable for making the CyberKnife treatment plan. 


\section{Cureus}

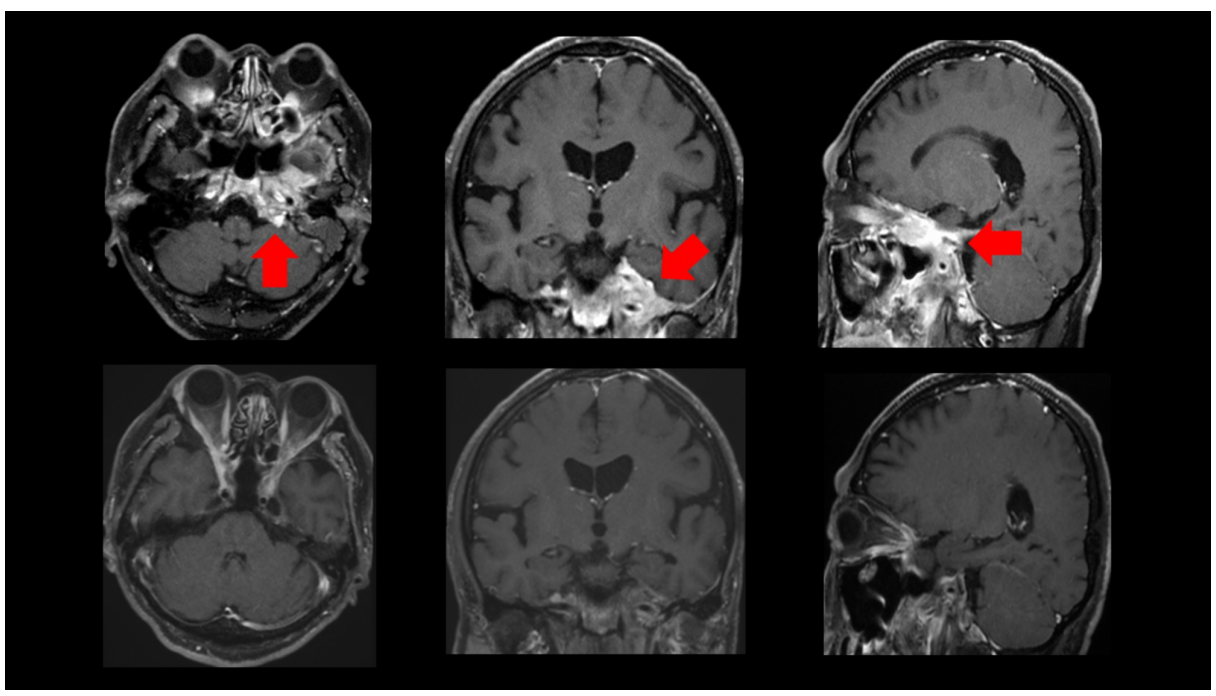

FIGURE 3: Contrast-enhanced MRI of Case 1

Contrast-enhanced MRI before CyberKnife (top) and after CyberKnife (bottom). The tumor in the petroclivus (red arrow) disappeared after treatment.

MRI: magnetic resonance imaging

Case 7 presented with diplopia after the therapy of lung cancer. Contrast-enhanced MRI revealed a small tumor in the petroclival area. The treatment plan of CyberKnife radiation therapy is shown in Figure 4.

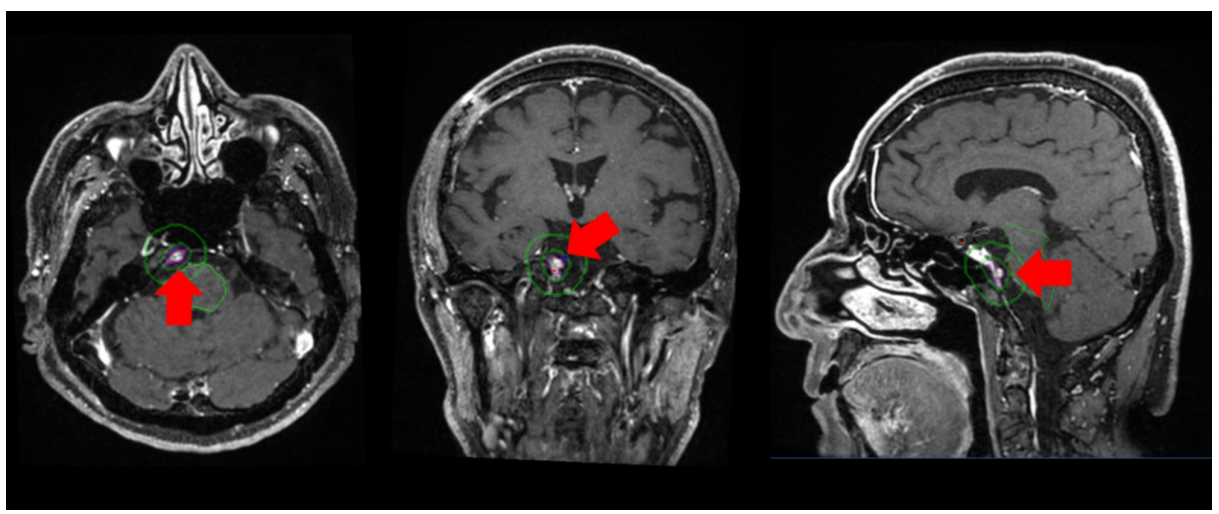

FIGURE 4: CyberKnife treatment plan of Case 7

Contour maps were drawn around the tumor (red arrow).

The tumor disappeared in six months as shown in Figure 5. Diplopia disappeared in only three months. 


\section{Cureus}

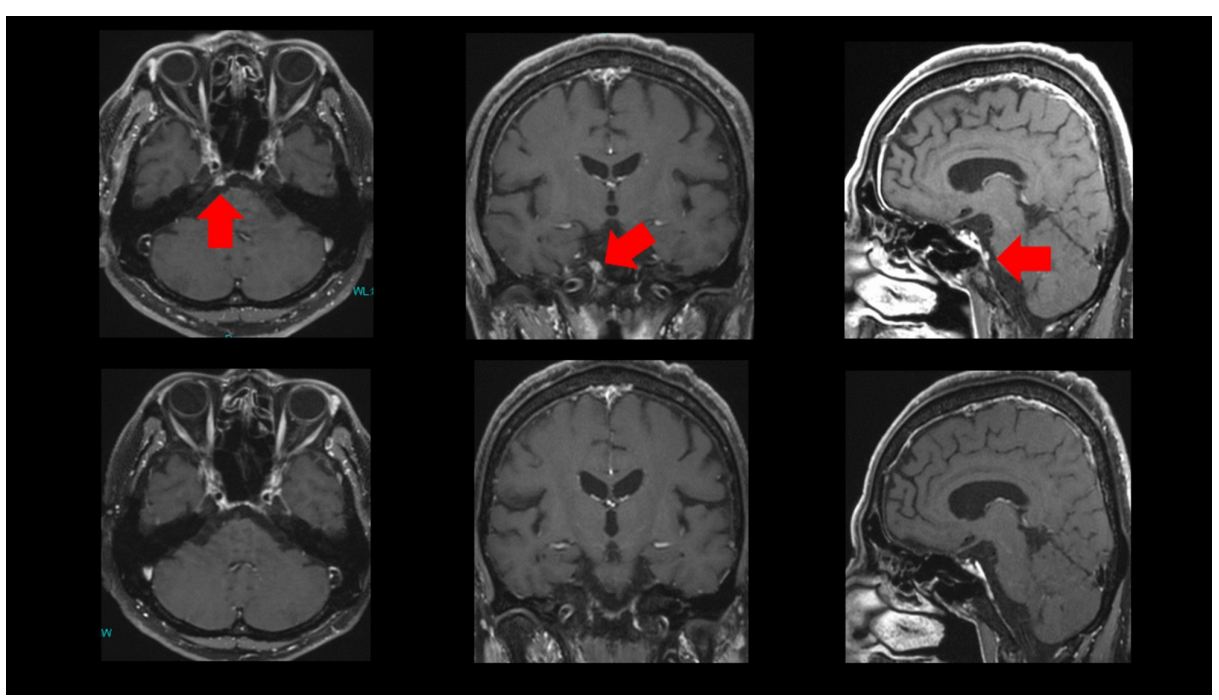

FIGURE 5: Contrast-enhanced MRI of Case 7

Contrast-enhanced MRI before CyberKnife (top) and after CyberKnife (bottom). The tumor located in Dorello's canal (red arrow) disappeared after treatment.

MRI: magnetic resonance imaging

\section{Discussion}

Dorello's canal is an osteofibrous passage formed by a narrow depression near the tip of the petrous bone, located behind Gruber's petrosphenoidal ligament, between the petrous apex and the clivus [3]. The abducens nerve passes through this canal. Dorello identified the enclosed region as a potential site of abducens nerve constriction, leading to abducent palsies [3-4]. Dorello's canal is widely recognized as a key landmark in skull base surgery of the petroclival region and holds clinical significance due to its relation to the abducens nerve and surrounding vascular structures $[3,5]$.

The abducens nerve is fully exposed from the posterior fossa through its entrance into Dorello's canal [6]. After entering Dorello's foramen, measuring 6 to $12 \mathrm{~mm}$ in length and 1 to $3 \mathrm{~mm}$ in width, the nerve is covered by a sleeve of dura propria for a variable distance (several millimeters) towards the cavernous carotid artery $[6,7]$. If cancer migrates into this canal, it will compress the abducens nerve to cause diplopia. It is, therefore, extremely difficult to remove the cancer from Dorello's canal even with microsurgery. Conventional radiation therapy typically requires 30-day treatment, whereas SRT with CyberKnife requires only several days. SRT also provides high precision in three dimensions. Furthermore, conventional radiation risks damaging surrounding tissues and organs, which are precluded with SRT. SRT is, therefore, clearly optimal with some special adjustment to critically avoid any damage to the abducens nerve in the canal.

There are several reviews about radiation therapy on skull base tumors. Chamoun and DeMonte wrote in their review that radiotherapy is the main form of treatment for skull base metastasis, and the general recommendation for radiotherapy is $35 \mathrm{~Gy}$ in 14 fractions over three weeks [8]. Clump et al. reported the efficacy of SRT, with the most common fractionated regimen being $24 \mathrm{~Gy}$ delivered in three fractions, which improved symptoms within one month [9]. Mori et al. reported that if skull base metastasis and skull base invasion are relatively localized, they can be good candidates for SRT [10]. However, optimal treatment protocols or guidelines have not yet been established. Due to the relative rarity of skull base metastases and complicated structures such as Dorello's canal, a radiation regimen needs to be composed for each patient [8].

Contrast MRI and FDG-PET have made it possible to detect small lesions of skull base metastases. The brain normally uptakes FDG while the non-cancerous skull does not. If the skull uptakes FDG, metastasis is demonstrated. FDG-PET also simultaneously reveals the location of primary cancer in the body. Therefore, FDG-PET is highly critical in detecting skull base metastasis and its primary cancer.

This study clearly demonstrates the successful treatment of diplopia by CyberKnife radiotherapy for skull base petroclival metastases. The keys of success were utilizing contrast MRI and FDG-PET for treatment planning and the hyper-fractionated method to avoid any damage to the abducens nerve compressed by tumors in Dorello's canal. 


\section{Conclusions}

Ten cases of diplopia due to petroclival metastases were successfully treated with CyberKnife SRT. The challenging treatment of these tumors was successful due to the precise detection of tumor locations by contrast MRI and FDG-PET and CyberKnife SRT.

\section{Additional Information}

\section{Disclosures}

Human subjects: Consent was obtained by all participants in this study. Animal subjects: All authors have confirmed that this study did not involve animal subjects or tissue. Conflicts of interest: In compliance with the ICMJE uniform disclosure form, all authors declare the following: Payment/services info: All authors have declared that no financial support was received from any organization for the submitted work. Financial relationships: All authors have declared that they have no financial relationships at present or within the previous three years with any organizations that might have an interest in the submitted work. Other relationships: All authors have declared that there are no other relationships or activities that could appear to have influenced the submitted work.

\section{Acknowledgements}

The authors wish to thank Dr. Paul W. Chin, Jr. for data analysis.

\section{References}

1. Greenberg HS, Deck MDF, Vikram B, Chu FCH, Posner JB: Metastasis to the base of the skull: clinical findings in 43 patients. Neurology. 1981, 31:530-537. 10.1212/wnl.31.5.530

2. Hayashi N, Mitsuya K, Deguchi S, Nakasu Y: Classification of clinical syndromes associated with skull-base metastasis in the MR era [Article in Japanese). No Shinkei Geka. 2018, 46:865-873. 10.11477/mf.1436203829

3. Reddy RK, Reddy RK, Jyung RW, Eloy JA, Liu JK: Gruber, Gradenigo, Dorello, and Vail: key personalities in the historical evolution and modern-day understanding of Dorello's canal. J Neurosurg. 2016, 124:224-233. 10.3171/2014.12.JNS14835

4. Dorello P: Considerations about the cause of temporary abducens paralysis in middle ear inflammation . Attidella Clinica Oto-Rino-Laringoiatrica. 1905, 3:209-217.

5. Kshettry VR, Lee JH, Ammirati M: The Dorello canal: historical development, controversies in microsurgical anatomy, and clinical implications. Neurosurg Focus. 2013, 34:E4. 10.3171/2012.11.FOCUS12344

6. Fukushima T, Day JD, Hirahara K: Extradural total petrous apex resection with trigeminal translocation for improved exposure of the posterior cavernous sinus and petroclival region. Skull Base Surg. 1996, 6:95-103. 10.1055/s-2008-1058650

7. Ambekar S, Sonig A, Nanda A: Dorello's canal and Gruber's ligament: historical perspective. J Neurol Surg B. 2012, 73:430-433. 10.1055/s-0032-1329628

8. Chamoun RB, DeMonte F: Management of skull base metastases. Neurosurg Clin N Am. 2011, 22:61-66. 10.1016/j.nec.2010.08.005

9. Clump DA, Leeman JE, Wegner RE, Burton SA, Mintz AH, Herton DE: Stereotactic radiosurgery for the treatment and palliation of base of skull metastases. J Radiosurg SBRT. 2013, 2:217-223.

10. Mori Y, Kida Y, Matsushita Y, Mizumatsu S, Hatano M: Stereotactic radiosurgery and stereotactic radiotherapy for malignant skull base tumors. Cureus. 2020, 12:e8401. 10.7759/cureus.8401 